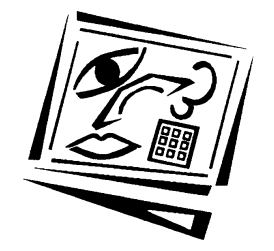

\title{
"A website for my subject": The experiences of some academics' engagement with educational designers in a team based approach to developing online learning materials
}

\author{
Geraldine Torrisi-Steele and Glenda Davis \\ Griffith University
}

\begin{abstract}
In recent years Australian universities have increased their focus on flexible delivery and online learning. Successful development of online teaching materials requires both knowledge of pedagogy as it applies to multimedia technologies as well as knowledge of the capabilities of current software and hardware. While academics are familiar with the skills and approaches required to operate in traditional environments they are often not equipped to meet the new demands of web authoring and online course design. Consequently, the potential of the online learning environment to improve the quality of the learning experience often remains unrealised.
\end{abstract}

To address this issue Griffith University, as part of its focus on flexible learning, has established campus based production centers. The center offers academics the services of multimedia development teams. An educational designer is allocated to work collaboratively with the academic to assist with the design of the online materials and the integration of the online resources into courses.

This paper explores the expectations, experiences and perceptions taken from the perspective of ten lecturers within Griffith University, as they engage with the educational designer to develop online learning materials. Motivated by the authors' belief that the development of online learning materials is an endeavour aimed at improving the quality of teaching and learning, this paper seeks to raise some of the issues and concerns which educational designers, as staff developers, need to consider in order to guide interactions with academic staff toward a more fruitful end.

\section{Introduction}

In recent years, many higher education institutions have adopted flexible learning. The interpretation of the flexible delivery concept is varied 
(McDonald and Postle, 1999). At Griffith University, the move towards flexible learning has, as is the case in a number of other institutions, lead to a focus on the development of online learning materials.

It must be stressed that flexible learning at Griffith University does not equate solely to online materials. However, the development of online materials by academics is considered a significant component of flexible learning and delivery. Throughout this paper, the context for discussion is the development of online learning resources, with the understanding that the development and use of the online learning resources is situated within the flexible learning context of Griffith University.

The advent of new technologies such as online learning is seen as an opportunity to challenge traditional approaches to university teaching. Academics are thus presented with a new context in which to undertake the business of teaching. While many of the skills which teaching staff have acquired in the past may be transferable to the new context, there is also the urgent need to provide support for staff to develop the skills and knowledge required to exploit potential teaching and learning advantages of the new mediums (Holt and Thompson, 1998). At Griffith University, educational designers provide one aspect of support for academics who are developing online materials. Allocated to work collaboratively with an academic, the educational designer provides support and guidance for the development and integration of online materials into the curriculum. Given the close working relationship educational designers establish with academics, it is important to recognise the significant role that the interaction with the educational designer occupies within the professional development activities of the academic.

Insight into academics' expectations, experiences and perceptions of the online materials development is critical in planning and structuring support that addresses academics needs and results in interactions with educational designers that culminate in positive changes to teaching practice. Towards gaining these insights we interviewed ten academics from various disciplines at Griffith University who working with an educational designer are undertaking the production of online materials.

\section{Context}

\section{Flexible learning}

Interpretation of the concept of flexible learning is "as elastic as the term itself" (Guiton, 1999, p. 51), and has been practiced in a diverse number of forms. Moran and Myringer (1999, p.60) recognise that as a concept, 
"flexible learning draws qualities or experiences from its three parents" namely, distance education, campus based education and information technologies. From distance education, flexible learning encompasses the idea that " education should go to people and not the other way around and harnesses...experience in designing student centred learning environments which include choosing technologies and materials appropriate to the learning purpose (Moran and Myringer, 1999, p.60). From campus based education, flexible learning recognises the importance of the interaction between teacher and learner and recognises the implications of technologies for "campus learning spaces and facilities" (Moran and Myringer, 1999, p.60). From information technologies, changes to the variety, amount and sources of information required for learning and the communications capabilities can be used to significantly reduce students' isolation from each other and their teachers (Moran and Myringer, 1999, p. 60). From this perspective, the flexible learning ideal may be defined as

Approaches to teaching and learning which are learner centred, free up the time, place and methods of learning and teaching and use appropriate technologies in a networked environment (Moran and Myringer, 1999, p. 60)

Taylor, Lopez and Quadrelli (1996) recognise flexible learning as a combination of "philosophy and technology" which embodies open learning concepts of student centred education, distance education delivery systems which allows off campus participation and the utilisation of information technologies.

\section{Challenging traditional teaching culture}

Given the combination of student centred philosophy and technology, espoused by flexible learning, flexible learning initiatives challenge traditional university teaching culture both in moving towards more student centred practices and in recognising the potential of new information technologies such as online learning as being "not just a more powerful tool for flexible learning... but as offering a new paradigm for learning in higher education" (Land, 1997, p.27)

\section{Traditional teaching culture}

Traditionally, academic culture espouses a teacher centred approach that to some degree creates student dependency. The student centred approach underlying flexible learning is in conflict with the traditional view.

The academic culture generally has the teacher as the central figure whereas flexibility places the student in control. The teachers set the curriculum and 
design the courses whereas flexibility approaches enable the student to choose the learning materials and set goals. (Koppi, Chalouplka, Llewellyn, Cheney, Clar and Fenton-Kerr, 1998, p. 425)

The view of learning as being student centred has been widely applied to the development of educational multimedia materials. Frequently referred to as the 'constructivism', the basic tenet is that learners actively construct knowledge rather than passively acquire it and that aim of teaching is to support the active construction of knowledge rather than simply communicating knowledge (Duffy and Cunningham, 1996). From this perspective, the design of online learning materials revolves about the learner. Consideration of learner characteristics including cultural aspects, prior knowledge and learning styles becomes of paramount importance. As opposed to traditional approaches where the content and transmission of content is the focus, the learner centred framework, such as that espoused by flexible learning, directs attention away from content in isolation to the students and how they will interact with the content in the learning environment being constructed.

\section{The role of technology}

Within Griffith University's implementation of innovative practice through flexible learning, the use of technology, particularly online learning materials is strongly advocated. However it is possible to introduce technologies such as online materials with minimal impact on the traditional teaching environment. New technologies may be used in ways that replicate traditional teacher centred approaches to learning and contribute little to improving the quality of student learning. The introduction of new technologies to the learning environment will only lead to innovation and improvement if the technologies are integrated into the curriculum rather than merely added on and used in a superficial way. Integration of technology into the curriculum can only take place if the teacher has "re-examined his or her approach to teaching and learning and adopts new strategies" (Tearle, Dillon and Davis, 1999, p. 10). The integration of technology in this way will often result in a redefinition of the teacher's role from "that of an instructor to enabler" (Tearle, Dillon and Davis, 1999, p.10).

If online learning materials are integrated with other instructional strategies in the curriculum then they have the potential to support the student centred approach by being an integral part of "knowledge spaces" which "allow users to explore as they wish" (Brown, 1997). Chickering and Ehrmann (1996) suggest that maximum positive impact of integrating 
new technologies into the tertiary curriculum can be achieved if technology is integrated on the basis of the Seven Principles for Good Practice in Undergraduate Education developed by Chickering and Gamson in 1987:

1. Good Practice Encourages Student-Faculty Contact

2. Good Practice Encourages Cooperation Among Students

3. Good Practice Encourages Active Learning

4. Good Practice Gives Prompt Feedback

5. Good Practice Emphasises Time on Task

6. Good Practice Communicates High Expectations

7. Good Practice Respects Diverse Talents and Ways of Learning (Chickering and Gamson, 1987)

The framework presented by Sandholtz, Ringstaff and Dwyer (1997) in the Apple Classrooms of Tomorrow program is useful as a basis for conceptualising how educators may achieve integration of technology in the learning environment beyond a superficial level. The framework suggests that the full integration of technology accompanied by significant changes in teaching practice is the third and final stage (transformation) of a continuum of adoption of technology in the learning environment. First stage of entry and the second of adaptation precede this third stage of transformation. At the entry stage there is an awareness of possibilities but there is no impact on teaching and learning practices. During the adaptation stage there is some evidence of integrating the technology into existing practices.

\section{Innovation requisites - reflection and support}

Given the contrast between traditional approaches and flexible learning environments, it is evident that a shift to flexible learning is a move towards innovation. Academic culture, has remained static and conservative, generally experiencing minimal change in response to driving forces (Koppi et al, 1998, Hannan, English and Silver, 1999). This minimal change extends to teaching activities. It is also recognised that university teaching is not always effective. While academics possess discipline knowledge, often a lack of awareness of teaching and learning results in the perpetuation of traditional teaching methods without reflection on the "appropriateness of such methods in bringing about high quality student learning" (Ballantyne, Bain and Packer, 1999 p. 237). The need for university teachers to reflect on their practice cannot be understated (Ballantyne et al, 1999). 
Laurillard (1999, p. 21) observes that such "wide ranging" innovation as flexible learning reverberates through every level of the organisation and as such "mechanisms, procedures and structures must create and sustain continual learning and adaptation with respect to the core activity of teaching". For staff, this shift to innovation is a call to reflect, to critically examine and to evaluate their current methods, to reshape and restructure teaching practice, integrating the new possibilities offered by technology in order to continually improve the quality of the learning environment. In order to achieve this "staff at all levels will need both proactive encouragement, and responsive support"(Laurillard, 1999, p. 21).

\section{The process of innovation}

Within the context of flexible learning initiatives as innovation, Havelock's notions about the innovation process provide a useful reference framework for individuals such as educational designers who are involved in some aspect of staff development. Havelock (1982) identifies the key support mechanism in the innovation process in education as being the change agent. According to Havelock (1982) individuals, irrespective of "formal job title", may act as a change agents in four primary ways: catalyst (to help overcome inertia), solution giver (knowing when and how to offer solutions), resource linker ("helps the client make best use of resources both inside and outside their own system"(p. 9)) and as process helper (how to solve the problem). The task of the change agent as a process helper is divided into six stages: Building a relationship between change agent and client, diagnosing the problem, acquiring relevant resources, gaining acceptance and stabilising the innovation and generating self renewal (Havelock, 1982).

\section{Flexible learning at Griffith University}

In Griffith University's Teaching and Learning Management Plan 1999-2001 (embedded within the Strategic Plan), flexible learning is targeted as one of the five areas for strategic development. flexible learning is seen as a key initiative within the University's goals and strategies for teaching and learning. The Teaching and Learning Management Plan states that:

Flexible learning is an extension of the University's commitment to, and history of, student focused teaching. The result is the development of employment related skills and the capacity for independent learning. While information technology is a core technology of flexible learning, there are 
many aspects and methodologies embraced within the concept of flexible learning that are not related to information technology. These may include flexibility as to assessment, time of access to resources, forms of credit or pacing.

While the general consensus is that there is no simple definition of flexible learning, teaching and learning objectives stated within the university's Strategic Plan 1999-2003 indicate that flexible learning encompasses "excellence in student centred learning" and is seen as a force for innovation in teaching and learning (Griffith University, 1999).

To support flexible learning initiatives Griffith University has established Griffith Flexible Learning Services (GFLS) and Griffith Institute of Higher Education (GIHE). GIHE's primary purpose is support for academic staff development. GFLS is comprised of the Administrative Support Unit and the Multimedia Unit.

\section{Support for staff developing online materials: The Multimedia Unit}

The Multimedia Unit is primarily concerned with the technology aspect of flexible learning.

The staff of the Multimedia Unit provides specialist advice in multimedia technical development and in educational design. Flexible learning subject development work is undertaken jointly with academics using a team based collaborative approach...

The key function of the Multimedia Unit within GFLS is the design and development of the full range of flexible learning resources including multimedia resources (CD-ROM and WWW delivered), print resources and stand alone audio and video resources. (Extract from the GFLS web pages, http: / / www.gu.edu.au/gfls)

\section{The educational designer role}

The Multimedia Unit staff includes a team of educational designers. The educational designers form large part of the interface between the academic and the production team. The educational designer's role is the provision of support and advice in the design, development and use of electronic (including online) and print media used for teaching and learning. (GFLS web pages, http:/ / www.gu.edu.au/gfls/frameset7.html)

Typically, once an academic has begun to engage in the development of online materials, an educational designer will be allocated to work collaboratively in the design and development of the resource. The advice provided by the educational designer may include: 
- the range of options available and the most appropriate technology to meet the needs of the target audience and achieve the purpose and desired outcomes;

- advantages and disadvantages of particular media;

- the integration of various resources with other teaching strategies to assist in the creation of a wide variety of flexible learning environments;

- effective design of learning resources including multimedia, print based and audio and video resources to enhance student outcomes;

- advice to support the development of submissions... (GFLS website, http: / / www.gu.edu.au/gfls / frameset7.html)

It follows that the interaction between the educational designer and the academic takes place in a context characterised by interplay among traditional academic teaching culture, personal philosophies of teaching and learning, and principles of teaching and learning which underpin student centred approaches to online learning.

\section{Approach}

The ten Griffith University academics interviewed were invited to participate in the interviews on the basis of their varied experiences with development of online learning. Included were academics from three campuses, from different disciplines (Information Technology, Human Services, Music, Arts, Business and Nursing) and with varying levels of experience in developing online materials for flexible learning (six had just completed one online subject, while the remainder had experience extending beyond one year, ranging from two to four online subjects developed). Participating academics had worked with a number of different educational designers. Those academics with whom the authors, as educational designers, had previously worked were avoided, since responses may have been colored by previous interactions with the interviewers. Academics participated voluntarily in the interviews.

Participating academics were informed prior to beginning the interviews of the context, that is, that the interviews were being conducted:

- In complete independence of university administration or any formal evaluations of either process or performance both on the part of academics and of the GFLS multimedia unit, and

- Purely as a research interest of both authors who have educational design backgrounds.

Interview duration was sixty to ninety minutes. The interview was semistructured with guiding questions organised into four main sections: 
Background - extent of use of technology for teaching and learning prior to engaging in flexible learning, reasons for engaging in flexible learning.

Preconceptions - Anticipated advantages and disadvantages of use of online materials; expectations of how online materials would be used and the impact the introduction of the materials would have on the teaching and learning environment, expectations about educational designer role.

Experiences during development - positive and challenging aspects of involvement in the production process; experience of the educational designer's role

Reflection - post production - satisfaction with final product; desirable changes to the production process; compare use of materials with the anticipated use; advantages and disadvantages of using the materials, impact on the teaching and learning environment; staff development needs.

Data obtained has been analysed below in terms of the main themes that arose.

\section{What the academics we interviewed had to say}

\section{Teaching and learning with online materials}

With three exceptions, all of the academics interviewed, stated that their involvement in the development of online materials was not voluntary but was required by senior administration. However, all of the academics perceived that the introduction of online learning materials could serve a useful purpose, to varying degrees, in their teaching and learning environment. The general sentiment being that while the directive to develop the online materials came from a head of school, "professional interest and curiosity was aroused...not unwilling to participate". When asked what they wanted to achieve with the website, (Table 1) the consistent top response was to improve student access to lecture materials.

If the responses in Table 1 are examined within the context of the stages of instructional evolution identified in the Apple Classrooms of Tomorrow program (Sandholtz et al, 1997) then it may be suggested that some academics are operating at the entry stage (website being used solely for access to materials with no impact on teaching and learning practice) while others are at the adoption or early transformation stages. Responses to questions about advantages and disadvantages of using online learning 
materials for teaching and learning (Table 2 below) reflected and reinforced this suggestion.

Table 1: Main themes in response to the question of what did you want to develop? (In order from most to least often given response)

- A website which provided access to lecture materials from different locations at any time thus reducing the need for students to attend lectures for example, if they have work or family commitments

- A website which provided access to course materials which students are expected to work through before attending classes so that they are better prepared

- A website which would provide some opportunity for more self paced, flexible learning. A website that students could move around in rather than work linearly and that would get them thinking...to really engage them

- A website which provided useable material that supported the students' ability to apply the skills to what they are learning

Not surprisingly, those academics whose responses suggested the use of technology beyond the entry stage, were those with the most experience in developing online materials. These staff members had developed two or more online subjects and their time of involvement in flexible learning was twelve months or greater. From the perspective of the educational designer this is significant in that it emphasises that the development of online material must be considered as a developmental process that 'takes time'. The interaction between the educational designer and the academic should be guided by the notion that total development of the online materials is in most instances an overlay of two processes: the process of development and design of the actual materials, and the process of reflection and evolution of teaching practice in the face of new possibilities offered by the technology; with reflection and evolution of teaching practice informing development and design of the materials.

\section{Production experiences}

When asked to identify the positive aspects of their involvement in the production process two main themes arose. Firstly, it was considered a challenging learning experience. This reinforces the notion that educational designers need operate with the understanding that the expectations and practice of teaching staff will evolve over time. Secondly, 'feeling part of the production team' was identified by all academics interviewed as a strong positive aspect of involvement. Academics' responses were also strongly positive to contact with other production 
team members as well as the educational designer. Those who did not experience this sense of team membership stated it as one of the more challenging aspects of their production experiences. Establishing team membership seemed to be important in not making teaching staff feel that they were merely the 'suppliers' of content and not fully participating in the design process.

Table 2: Summary of responses relating to perceived advantages and disadvantages of online learning materials for teaching and learning. In order from most to least often given

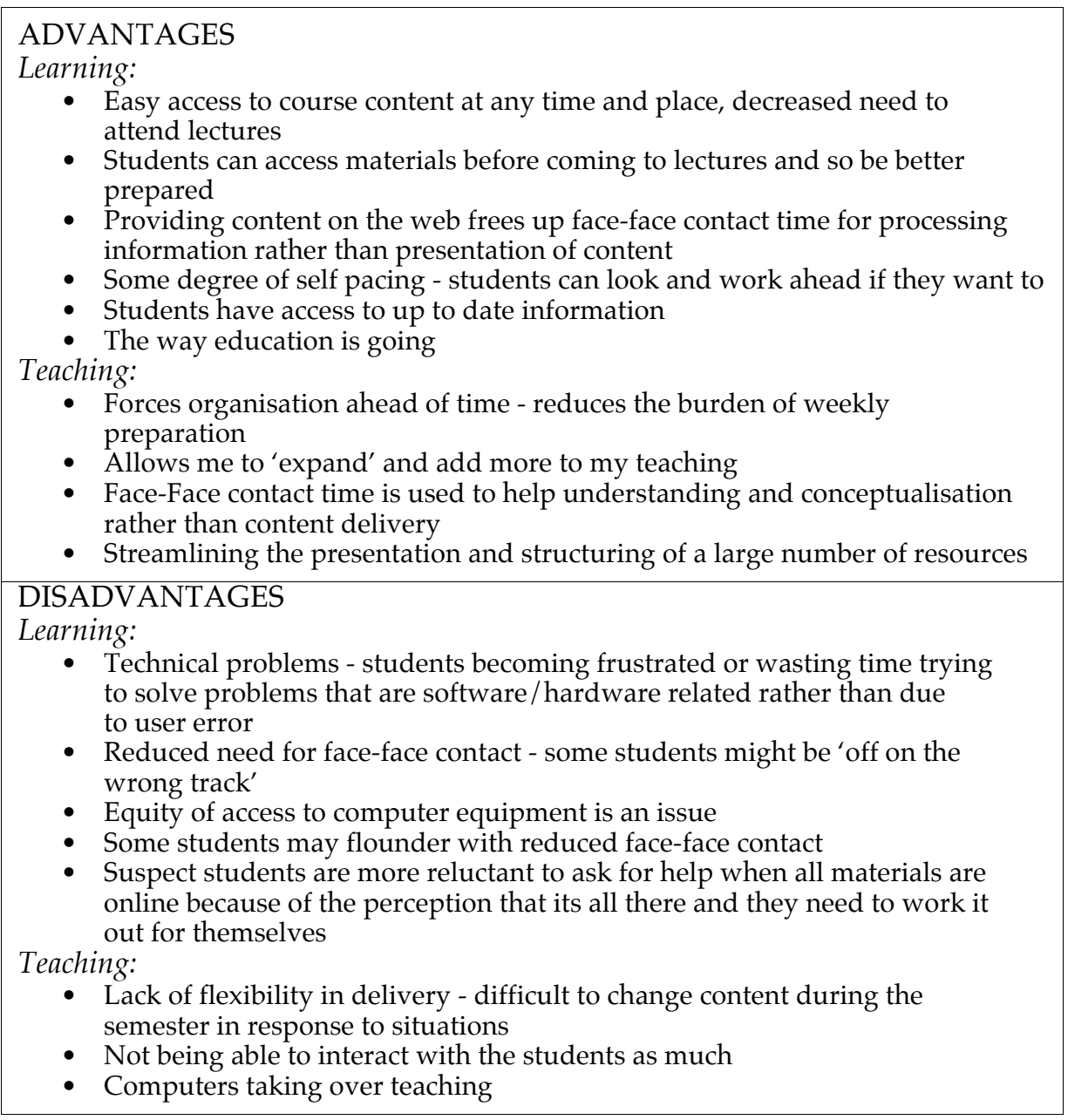


Responses to questions regarding the production experiences (Table 3 below) suggest that two major challenges and concerns faced by the academics interviewed were time frames and a perceived lack of knowledge about 'how it works' and 'what is possible'. From the educational designer's perspective it is important to recognise, be sympathetic and address in the best way possible these concerns. Failure to recognise and address these concerns can be detrimental to the successful outcome of the development exercise. Innovations can have a "punitive effect" as workload may increase dramatically and confronting the new contexts can undermine confidence and feelings of competence (Hannan, English and Silver, 1999, p. 279).

Table 3: Summary of responses related to concerns at the beginning of production, positive and challenging experiences during production. In order from most to least often given.

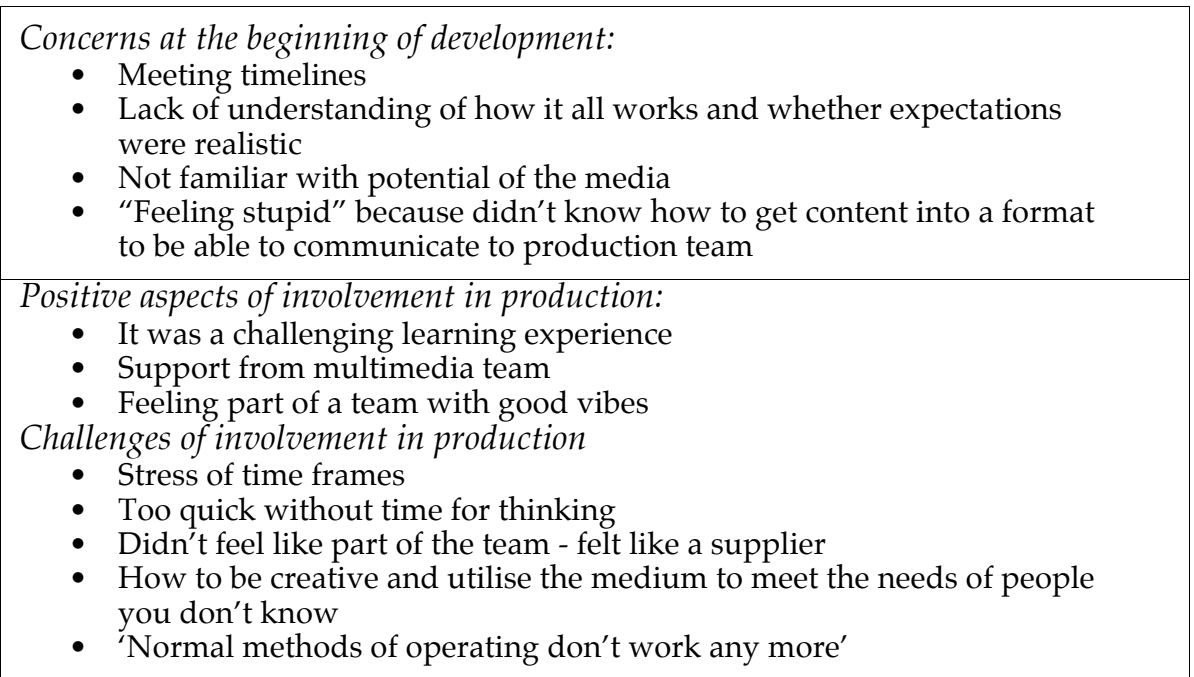

\section{Experiences of interaction with the educational designer}

Responses suggest that the group of academics interviewed perceived the educational designer to have an advisory role in varying degrees (Table 4 below). The teaching staff interviewed considered the ability of the educational designer to act as a sounding board for their ideas and the establishment of a collaborative working relationship to be of utmost importance. The ability of the educational designer to provide insight into the technical capabilities of the online media was also considered important. 
Queried about the importance of the educational designer providing support for the development of the whole curriculum, not just online materials, the response was that this was not considered an important aspect of their interaction with the educational designer. As was noted previously, among those interviewed, the degree of integration of the technology into teaching and learning practice has generally not evolved to the point of being a catalyst for major changes in practice. It would be anticipated that as technology and the concept of flexible learning is integrated to a greater degree, focus in the interactions between educational designer and teaching staff may well shift attention more towards the total curriculum. Using the seven principles of good practice (Chickering and Gamson, 1987) as part of the framework for material development may serve to expand focus beyond the immediate task of online material development to a more integrated approach of curriculum development. This wider focus will be more conducive to reflection and transformation of practice.

Table 4: Summary of responses relating to experiences of interaction with educational designer role

- I would provide content - educational designer would help massage it into a more suitable format, educational designer translates my content into web medium

- As the lecturer I gave advice on how the website would be which was then implemented by production

- Educational designers as advisers which suggest presentation strategies

- Educational designer would be there to help develop materials in the most efficient way and promote learning

- Educational designer would provide guidance as to what was possible and how to best present the materials on the web

- Educational designer as a sounding board to help develop my ideas

- Ed Des as being in a vetting role and ensuring materials were suitable and met quality assurance

- A collaborative relationship both taking active roles in designing and presenting material

\section{If I knew then what I know now...}

Asked the question "What do you know now that you wish you had known before you began production?" the consistent first response was to know more about the capabilities and potential of online media. This response was accentuated when asked about professional development needs (Table 5 below). The opportunity to investigate software and materials already available and the opportunity to access others' experiences in developing online materials for flexible learning were 
considered important from a professional development perspective. While specific workshops and situations can be set up explicitly for professional development purposes in this area, we suggest that the educational designer works within the context of interaction with teaching staff to address the problem of understanding more about the potential of online media and providing. The educational designer role being defined not just within the parameters of an 'adviser' but extending further to include the notion of facilitating professional development.

The second most requested area of support was web page construction. This request was more directed towards being able to easily update the website themselves rather than towards developing the website itself. Although we are dealing here with the limited case of a few academics, these responses reflect findings such as those presented by Ellis, O'Reilly and Debreceny (1998, p.197) which indicate that "staff are primarily interested in both pedagogical issues of online delivery and the skills necessary to design Web pages".

In terms of organisational support, the common request was time release from teaching load. The stress of the time frames was given as one of the major challenges in the production experience (Table 3) not only in terms of having material ready to meet deadlines but as some of the academics stated, time required to think more about material design.

Table 5: Summary of comments related to professional development and support

- Would like to have known more about the capabilities of online media before we started

- I need to learn to be more creative to use this medium better

- Time to investigate what software and materials are already available

- Access to others' experiences in developing online materials for flexible learning

- The two day retreat was good

- Went to workshops. This was useful

- Learn technical aspects of creating html pages

- Training in web page construction

- Learning to update own html pages

- Time release from teaching to develop materials

- Ongoing technical support

Perhaps the most valuable comment about professional development requirements was made by several of the teaching staff interviewed, at the end of the interview sessions, as 'thank yous' were being said: 'This has been a good debriefing session... I haven't had time to do that' and 'This has given me a chance to think about it'. It was discussed earlier that 
participation in flexible learning is a call to innovation and that the need for university teachers to reflect on their practice cannot be understated (Ballantyne et al, 1999). Reflection fuels innovation and as such, educational designers and professional development programs aiming to transform teaching practice need to focus not purely on the capabilities of the technology but also on fostering reflective practice. Professional development initiatives that consider only creative ways of including technology will not support transformation of teaching practice unless accompanied by critical reflection on current practice.

The crux of the matter for the educational designer is make explicit that the development of online materials is not simply a translation from one medium to another rather a transformation. The view that development of online materials is simply translation of content from one medium to another seemed to be held by some of the teaching staff interviewed. Notably these were those staff who were relatively new to the experience of developing online materials. In contrast, comments by the staff member with the longest involvement in developing online materials (two years, currently developing her fifth subject) suggested that was now viewing the process as challenging and transformational. She stated

\footnotetext{
I'm now going through a deconstruction process... and as I do it gets more challenging in a positive way...I suspect that the way I was previously thinking about my subject area was tied up with lecturing and writing...flexible learning has required that I rethink strategies...
}

The staff member went on to say that, while initially she has seen the website as a way of simply providing content thus freeing up face-face time for process thinking, she is beginning to realise that the website can be used to promote process thinking as well. She intends to implement this into the design of the subject she is currently developing. This staff member described the task of arriving at these conclusions to be 'enormously difficult'. The obvious implication of these comments for the educational designer is to consider how this journey of thought might be facilitated. As already discussed, encouraging reflection on practice is critical. We suggest that a platform for encouraging reflective practice can be established if the educational designer works with the aim of helping teaching staff to view the move to online delivery as a complex process. "Very few academics appreciate the fact that migration to a web based delivery mode of their course materials which they have in the past delivered in face to face mode is an involved process" (Porter and Corderoy, 1998, p. 572). 


\section{Summary}

Flexible learning is a key initiative within Griffith University's Teaching and Learning Management Plan. The move to flexible learning is seen as a call to innovation in teaching practice, the integration of online learning materials being a significant (but not only) component of, and catalyst for, innovative, student centred teaching practice. We have argued that if online materials are to serve as a catalyst for the innovation of teaching practice then the use of online learning materials is to go beyond the superficial level of merely being 'tacked on' to a deeper level of integration which results in significant transformations in teaching practice. This level of integration requires support and reflection on current practice.

Against this background, the comments made by the academic staff interviewed in this limited case, serve to provide some insight into professional development needs and considerations which the educational designer might address in working with academics to develop online learning materials in order to maximise the success of the interaction. These considerations are summarised below.

\section{Professional development}

Although we are dealing here with the limited case of a few academics, responses to the question of most desired professional development reflect findings such as those presented by Ellis, O'Reilly and Debreceny (1998) which indicate that staff are primarily interested from the pedagogical perspective, in learning about the potential of the online medium and from a technical perspective in the skills necessary to build Web pages. Workshops, exploration of materials already developed and access to other's experiences were some of the approaches suggested for professional development.

\section{Considerations for educational designers}

- The interaction with the academic proceeds on the conceptualisation of the process of development as a complex transformation rather than simple translation of teaching materials. This idea of development as a process needs to be made explicit

- The development of online materials might be conceptualised as an overlay of two processes: that of material design and development and that of changes occurring in how the academic thinks about teaching and learning. 
- Assisting with an integrated approach to curriculum development, conducive to transformation by bringing frameworks such as the seven principles of good practice (Chickering and Gamson, 1987) to bear on the process.

- Empathising and addressing teaching staff's concerns arising from the pressure of innovation (time, workload, confidence)

- Fostering collaboration and strong team support in the development experience

- The role of the educational designer as described by the multimedia unit at Griffith University, shares some of the basic characteristics of a change agent as characterised by Havelock (1982). It seems appropriate that educational designers are perceived as change agents with an active role in professional development of teaching staff, thus in facilitating innovation, rather than simply acting as an 'adviser'

- Promoting reflection

As one of the academics interviewed put it: "it takes time to 'rejig' thinking". A shared understanding of this reality should shape the interaction between educational designer and academic. Arriving at this shared understanding may be considered a critical point in determining the outcome of the interaction between academic and educational designer. In building a foundation for change, the educational designer must adopt strategies which foster reflective practice by engaging teaching staff to "question assumptions and practices that seem to make [their] teaching lives easier but actually work against [their] own best interests" (Brookfield, 1995, p.8). This can be challenging. As Bereiter and Scardamalia (1993, p.109) argue, although experience can lead to intuitive expertise through routinising, it may also lead to resistance to new ways of doing things. From this perspective educational designers must direct staff development efforts towards what Bereiter and Scardamalia (1993) call progressive problem solving, that is, tackling problems that increase expertise rather than reducing problems to previously learned routines.

\section{References}

Ballantyne, R., Bain, J. D. \& Packer, J. (1999). Researching university teaching in Australia: Themes and issues in academics' reflections. Studies in Higher Education, 24 (2), 237-257.

Bereiter, C., \& Scardamalia, M. (1993). Surpassing Ourselves: An Inquiry Into the Nature and Implications of Expertise. Chicago: Open Court. 
Brookfield, S. (1995). Becoming a Critically Reflective Teacher. San Francisco: JosseyBass Publishers.

Brown, T. (1997). Multimedia in Education - Conclusions. University of New England. http: / / scs.une.edu.au / Units / CurricSt/CSIT513/573/573_12.html [viewed 27 Sept 1999, verified 12 Nov 2000].

Chickering, A. \& Ehrmann, S. C. (undated). Implementing the Seven Principles: Technology as Lever. http:/ / www.tltgroup.org/programs / seven.htm [9 April 2000]

Chickering, A. W. \& Gamson, Z. (1987). The Seven Principles for Good Practice in Undergraduate Education. http: / / ag.arizona.edu/futures/seven.html [viewed 9 April 2000, verified 12 Nov 2000]

Duffy, T. M. \& Cunningham, D. J. (1996). Constructivism: Implications for the design and delivery of instruction. In D. H. Jonassen (Ed), Handbook of Research for Educational Communications and Technology, 177-190. NY: Macmillan Library USA.

Ellis, A., O'Reilly, M. \& Debreceny, R. (1998). Staff development responses to the demand for online teaching and learning. Conference Proceedings ASCILITE '98, 191-201. http:/ / www.ascilite.org.au / conferences / wollongong98/asc98pdf/ellis0005.pdf [viewed 15 April 2000, verified 12 Nov 2000]

Griffith Flexible Learning Services (1999). Multimedia Unit website http:/ / www.gu.edu.au/gfls / [15 April 2000]

Griffith University (1999). Griffith University Strategic Plan - A Plan for the New Millennium 1999-2003. [viewed 15 April 2000, verified 12 Nov 2000] http: / / www.gu.edu.au/ua/aa/sp/sp/content/submenu/TaL.html

Griffith University (1999). Teaching and Learning Management Plan. http:/ / www.gu.edu.au/ua/aa/tal/home.html [15 April, 2000]

Guiton, P. (1999). Professional reflective practice and lifelong learning, In H. Keith (Ed), Higher Education Through Open and Distance Learning, 48-56. London: Routledge.

Hannan, A., English S., \& Silver, H. (1999). Why innovate? Some preliminary findings from a research project on 'Innovations in Teaching and Learning in Higher Education'. Studies in Higher Education, 24(3), 279-289.

Havelock, R. (1982). The Change Agent's Guide to Innovation in Education. Englewood Cliffs: Educational Technology Publications.

Holt, D. M. \& Thompson, D. J. (1998). Managing information technology in open and distance higher education. Distance Education. 19(2), 197-216. 
Koppi, A. J., Chalouplka, M. J., Llewellyn, R., Cheney, G., Clark, S., \& Fenton-Kerr, T. (1998). Academic Culture, Flexibility and the National Teaching and Learning Database. Conference Proceedings ASCILITE '98, 425-432. http: / / www.ascilite.org.au / conferences / wollongong98/asc98pdf/ koppi0059.pdf [viewed 15 April 2000, verified 12 Nov 2000]

Land, R. (1997). Virtually there: Flexible Learning in the New Millennium. In C. Bell, M. Bowden \& A. Trott (Eds), Implementing Flexible Learning, 15-42. London: Kogan Page.

Laurillard, D. (1999). Components of a Flexible Learning Methodology - Draft Working Paper. In P. Taylor \& G. Joughin (Eds), What is Flexible Learning? Teaching Through Flexible Learning Resources, 4-7. Brisbane: Griffith Institute of Higher Education.

McDonald, J., \& Postle, G. (1999). Teaching online: Challenge to a reinterpretation of traditional models. Conference Proceedings Fifth Australian World Wide Web Conference, Southern Cross University [verified 12 Nov 2000] http: / / ausweb.scu.edu.au/aw99/ papers/mcdonald/ paper.htm

Moran, L. \& Myringer, B. (1999). Professional reflective practice and lifelong learning, In H. Keith (Ed), Higher Education Through Open and Distance Learning, 57-61. London: Routledge.

Porter, A \& Corderoy, R. (1998). “There is only two weeks to go, can I get my subject onto the web?": A case study. Conference Proceedings ASCILITE '98, 571583. http: / / www.ascilite.org.au/conferences/ wollongong98/asc98pdf/portercorderoy0007.pdf [verified 12 Nov 2000]

Sandholtz, J., Ringstaff, C. \& Dwyer, D. (1997). Teaching with Technology. New York: Teachers College Press.

Taylor, P. G., Lopez, L. \& Quadrelli, C. (1996). Flexibility, Technology and Academics' Practices: Tantalising Tales and Muddy Maps. Brisbane: Griffith Institute For Higher Education.

Tearle, P., Dillon, P., \& Davis, N. (1999). Use of information technology by English university teachers. Developments and trends at the time of the National Inquiry into Higher Education. Journal of Further and Higher Education, 23(1), 515.

Geraldine Torrisi-Steele, School of Information Technology, Griffith University g.torrisi@mailbox.gu.edu.au Glenda Davis, Multimedia Unit, Griffith University glenda.davis@mailbox.gu.edu.au 